\title{
A Review of CAM for Procedural Pain in Infancy: Part II. Other Interventions
}

\author{
Jennie C. I. Tsao', Subhadra Evans ${ }^{1}$, Marcia Meldrum², Tamara Altman ${ }^{1}$ and \\ Lonnie K. Zeltzer ${ }^{1}$ \\ ${ }^{1}$ Pediatric Pain Program, Department of Pediatrics, David Geffen School of Medicine at UCLA, and ${ }^{2}$ John \\ C. Liebeskind History of Pain Collection, Louise M. Darling Biomedical Library, UCLA, Los Angeles, CA, USA
}

\begin{abstract}
This article is the second in a two-part series reviewing the empirical evidence for complementary and alternative medicine (CAM) approaches for the management of pain related to medical procedures in infants up to 6 weeks of age. Part I of this series investigated the effects of sucrose with or without non-nutritive sucking (NNS). The present article examines other CAM interventions for procedural pain including music-based interventions, olfactory stimulation, kangaroo care and swaddling. Computerized databases were searched for relevant studies including prior reviews and primary trials. Preliminary support was revealed for the analgesic effects of the CAM modalities reviewed. However, the overall quality of the evidence for these approaches remains relatively weak. Additional well-designed trials incorporating rigorous methodology are required. Such investigations will assist in the development of evidence-based guidelines on the use of CAM interventions either alone or in concert with conventional approaches to provide safe, reliable analgesia for infant procedural pain.
\end{abstract}

\section{Introduction}

Recent evidence suggests that the popularity of complementary and alternative medicine (CAM) in pediatric populations is growing (1). Estimated prevalence rates of CAM use in the general population of children across all age groups has varied from a low $2 \%$ (2) to $20-30 \%$ $(3,4)$. However, among children with chronic illnesses who do not always respond well to conventional treatments, such as cancer, rheumatoid arthritis and cystic fibrosis, CAM use has been reported at much higher rates, ranging from $30-73 \%(5-7)$.

One limitation of these prior estimates is that rates of CAM use have not been reported separately for infants versus older children. As a result, it has been difficult to accurately estimate the prevalence of CAM use in infants. In a rare investigation, Bellas and colleagues (8) recently

For reprints and all correspondence: Jennie C. I. Tsao, PhD, Pediatric Pain Program, Department of Pediatrics, David Geffen School of Medicine at UCLA, 10940 Wilshire Blvd., Suite 1450, Los Angeles, California 90024. Tel: 310-824-7667; Fax: 310-824-0012;

E-mail: jtsao@mednet.ucla.edu examined prevalence rates for consulting CAM practitioners according to the age of the child in Washington state (where private health insurance is mandated to provide coverage for CAM therapies). Using insurance claims data, Bellas et al. found that the rate of CAM consultation for infants (0-1 years) was $3.2 \%$. The therapies most frequently administered to infants were chiropractic care $(1.8 \%)$ and naturopathic medicine $(1.4 \%)$, while very small numbers $(\leq 0.1 \%)$ received acupuncture or massage. CAM usage rates were found to be similar between infants and children aged $2-5$ years $(3.0 \%)$. On the other hand, the use of CAM was found to increase among older children $(6-12$ years: $5 \%$; $13-17$ years: $9.8 \%$ ). Children with back pain and cancer had the highest percentage of CAM use, but the prevalence of CAM use within these diagnoses was not analyzed by age. These findings indicate that CAM is being sought for a small percentage of infants, although the reasons for such CAM use were not specified.

Although there has been no systematic evaluation of the prevalence of CAM use for acute, procedural pain in hospitals and neonatal intensive care units (NICUs), 
a number of investigators have begun to examine the potential benefits of CAM for managing pain related to medical procedures in infants. In recent years, pediatricians, nurses and parents have raised increasing concerns about the number of painful medical procedures that infants, especially preterm neonates in the NICU, must undergo (9). There is also growing concern about the potential risks of alleviating infant pain with conventional, pharmacologic agents. Thus, alternative, nonpharmacological approaches for the relief of procedural pain in these vulnerable patients have attracted new interest. Whereas there have been several previous reviews summarizing the literature on the efficacy of CAM approaches for acute and chronic pain in children (10-13), relatively few reports have focused on infants. This article is the second in a two-part series reviewing available evidence on the efficacy of CAM interventions for relief of procedural pain in infants. Part I of this series examined sucrose, and other sweet substances with or without non-nutritive sucking (NNS). This article investigates other CAM modalities for the management of procedural pain in infancy. The authors were unable to identify investigations evaluating the use of CAM for other pain problems (e.g. organic pain) in this age group.

\section{Methods}

The PubMed, PsychInfo, CINAHL and Cochrane Library databases searched up to August 2006 using the keywords: 'pain,' 'infant,' 'infancy,' 'neonate,' 'newborn,' 'baby' and 'babies.' Infants included newborns between a few hours and 6 weeks old; research, examining pain in older children was excluded (see Tsao and Zeltzer,2005 (1) for a review of CAM approaches for pain in older children). The focus of this article is to provide an overview of the published data regarding CAM approaches other than sucrose and sweet solutions, with or without NNS (reviewed in Part 1) for procedural pain in infancy. Studies were included if they possessed a control group or a comparison condition (e.g. at least one other intervention). The evidence for each CAM intervention is grouped together in separate sections subsequently (e.g. music therapy; kangaroo care (KC)). Within each CAM approach, reports examining similar procedures (e.g. heel lance) are discussed together. Results of the trials included in this review are summarized in Table 1.

\section{Summary}

\section{Music Therapy}

The results of reports on the effects of music for procedural pain in infants are summarized in Table 1 .
Music has long been used to enhance well being and to assist in alleviation of pain and suffering (14). Music can be distinguished from noise in that the latter exists without controls for volume, duration or cause/effect relations $(14,15)$. Exposure to excessive noise has resulted in documented adverse health effects including sleep disturbance and increased heart rate in infants hospitalized in the NICU (16). The clinical application of music may involve music therapy delivered by trained music therapists during live performances, or as recorded music delivered via headphones or speakers. Music is thought to exert its primary analgesic effect indirectly by distraction of attention from the pain of the medical procedure; distraction may also facilitate habituation (17). The underlying assumption is that when attention is occupied with another strong stimulus (i.e. music), the individual undergoing the painful medical procedure will be less able to process painful stimuli (18).

\section{Qualified Support for the Benefits of Music for Minor Procedural Pain}

Butt and Kisilevsky (2000) (19) examined preterm infants in the NICU who received two heel sticks either with music (recorded lullabies) or without music within a crossover design. Pain responses were assessed using The Neonatal Facial Coding System (NFCS)(20), an established instrument which has shown good reliability (21) and validity (20-22). Inter-rater reliability among coders in this trial was high. Older infants (post-conceptual age greater than 31 weeks) were reported to evidence a more rapid recovery in physiology and behavior during the music condition compared to no music. One key limitation is that possible order effects were not explicitly reported, and it is conceivable that sensitization or habituation may have occurred on the second heel stick.

In a novel investigation, Bo and Callaghan (2000) (23) tested the effects of NNS, music therapy, combined NNS and music therapy and no intervention control on full-term and preterm neonates undergoing heel stick. Compared to the control group, all three interventions led to significant reductions in pain as measured by the Neonatal Infant Pain Scale (NIPS) (24). However, the combined NNS and music therapy condition evidenced the greatest effect on pain behavior, whereas music alone resulted in the largest reduction in heart rate. The utility of these findings are limited by a lack of information regarding random assignment. Moreover, the raters who assessed pain behaviors were aware of group assignment, and this may have biased their ratings of pain response.

\section{Mixed Results for the Effects of Music on Circumcision Pain}

Early work by Marchette et al. (1991)(25) examined the impact of music on full-term neonates undergoing 
Table 1. Results of the CAM interventions reviewed for procedural pain in infancy

\begin{tabular}{|c|c|c|c|c|c|c|c|}
\hline Study & Procedure & Participants & Randomized & CAM approach & Control & Outcome measures & Findings \\
\hline $\begin{array}{l}\text { Marchette et al. } \\
\text { (1991) }\end{array}$ & Circumcision & 20 & Yes & $\begin{array}{l}\text { Music } \\
\text { i) Classical music } \\
\text { ii) Intrauterine sounds } \\
\text { iii) Pacifier } \\
\text { iv) Mmusic + pacifier } \\
\text { v) IU sounds + pacifier }\end{array}$ & Standard care & $\begin{array}{l}\text { NBAS } \\
\text { physiological variables }\end{array}$ & No differences \\
\hline $\begin{array}{l}\text { Butt and Kisilevsky } \\
(2000)\end{array}$ & Heel stick & 14 preterm & Yes & $\begin{array}{l}\text { Music } \\
\text { 1) Female sung lullaby } \\
\text { 2) Instrumental }\end{array}$ & No music & $\begin{array}{l}\text { NBAS- arousal } \\
\text { NFCS } \\
\mathrm{HR} \\
\mathrm{SaO} 2\end{array}$ & $\begin{array}{l}\text { Recovery- HR, arousal, pain } \\
\text { behaviors: music groups }>\text { control } \\
\text { (for infants }>31 \text { wks) }\end{array}$ \\
\hline $\begin{array}{l}\text { Bo and Callaghan } \\
(2000)\end{array}$ & Heel stick & $27 \mathrm{IC}$ & $?$ & $\begin{array}{l}\text { Music } \\
\text { 1) Pacifier } \\
\text { 2) Pacifier }+ \text { music } \\
\text { 3) Music }\end{array}$ & Standard care & $\begin{array}{l}\text { NIPS } \\
\text { HR } \\
\text { TcPao2 }\end{array}$ & $\begin{array}{l}\text { Pain: music }+ \text { pacifier }<\text { others } \\
\text { HR: music }<\text { others } \\
\text { TcPao2: music }+ \\
\text { pacifier }>\text { others }\end{array}$ \\
\hline Joyce et al. (2001) & Circumcision & 23 & Yes & $\begin{array}{l}\text { Music } \\
\text { 1) Llullaby } \\
\text { 2) EMLA }\end{array}$ & $\begin{array}{l}\text { i) Blank CDs } \\
\text { ii) Placebo cream }\end{array}$ & $\begin{array}{l}\text { RIPS } \\
\text { HR } \\
\text { Respiratory rates } \mathrm{SaO} 2\end{array}$ & $\begin{array}{l}\text { Pain: music }<\text { others } \\
\text { Oxygen: music }>\text { control }\end{array}$ \\
\hline Gray et al. (2000) & Heel stick & 30 term & Yes & $\begin{array}{l}\mathrm{KC} \\
\text { (held by mothers) }\end{array}$ & Swaddled in crib & $\begin{array}{l}\text { Crying, grimacing } \\
\text { HR }\end{array}$ & $\begin{array}{l}\text { Crying, grimacing: } \mathrm{KC}<\text { control } \\
\text { HR recovery: } \mathrm{KC}<\text { control }\end{array}$ \\
\hline $\begin{array}{l}\text { Johnston et al. } \\
\text { (2003) }\end{array}$ & Heel stick & 74 preterm & Yes & $\begin{array}{l}\mathrm{KC} \\
\text { (held by mothers) }\end{array}$ & swaddled in crib & $\begin{array}{l}\text { PIPP } \\
\text { HR } \\
\text { Oxygen levels }\end{array}$ & $\begin{array}{l}\text { Pain: } \mathrm{KC}<\text { control } \\
\text { (first } 90 \mathrm{~s} \text { after lance) }\end{array}$ \\
\hline $\begin{array}{l}\text { Goubet et al. } \\
\text { (2003) }\end{array}$ & $\begin{array}{l}\text { i)Heel stick } \\
\text { ii)Venipuncture }\end{array}$ & 51 preterm & Yes & $\begin{array}{l}\text { Olfactory stimulation } \\
\text { Familiar odor }\end{array}$ & $\begin{array}{l}\text { i) Unfamiliar odor } \\
\text { ii) Standard care }\end{array}$ & $\begin{array}{l}\text { Crying, grimacing, head } \\
\text { movements }\end{array}$ & $\begin{array}{l}\text { Heel stick: no differences } \\
\text { Venipuncture: crying: } \\
\text { familiar }<\text { unfamiliar }<\text { control }\end{array}$ \\
\hline Rattaz et al. (2005) & Heel stick & 44 term & Yes & $\begin{array}{l}\text { Olfactory stimulation } \\
\text { i) Mother's milk } \\
\text { ii) Vanilla odor }\end{array}$ & $\begin{array}{l}\text { i) Unfamiliar odor } \\
\text { ii) Standard care }\end{array}$ & $\begin{array}{l}\text { Head movements } \\
\text { Crying, grimacing }\end{array}$ & $\begin{array}{l}\text { Movement: mother's } \\
\text { milk < control }\end{array}$ \\
\hline Corff et al. (1995) & Heel stick & 30 preterm & Yes & Swaddling & Standard care & $\begin{array}{l}\text { Sleep state } \\
\mathrm{HR} \\
\mathrm{SaO} 2\end{array}$ & $\begin{array}{l}\text { HR, crying time, sleep disruption } \\
\text { time, sleep state changes after heel } \\
\text { stick: swaddling }<\text { control }\end{array}$ \\
\hline $\begin{array}{l}\text { Fearon et al. } \\
\text { (1997) }\end{array}$ & Heel stick & 15 preterm & $?$ & Swaddling & Standard care & $\begin{array}{l}\text { NBAS } \\
\mathrm{HR} \\
\text { Temperature } \\
\mathrm{SaO} 2\end{array}$ & $\begin{array}{l}\text { No differences during procedure } \\
\text { After: pain, HR: swaddled } \\
\text { < control (especially for older } \\
\text { infants) }\end{array}$ \\
\hline Huang et al. (2004) & Heel stick & 32 preterm & Yes & Swaddling & Containment & $\begin{array}{l}\mathrm{PIPP} \\
\mathrm{HR} \\
\mathrm{SaO} 2\end{array}$ & No differences \\
\hline
\end{tabular}




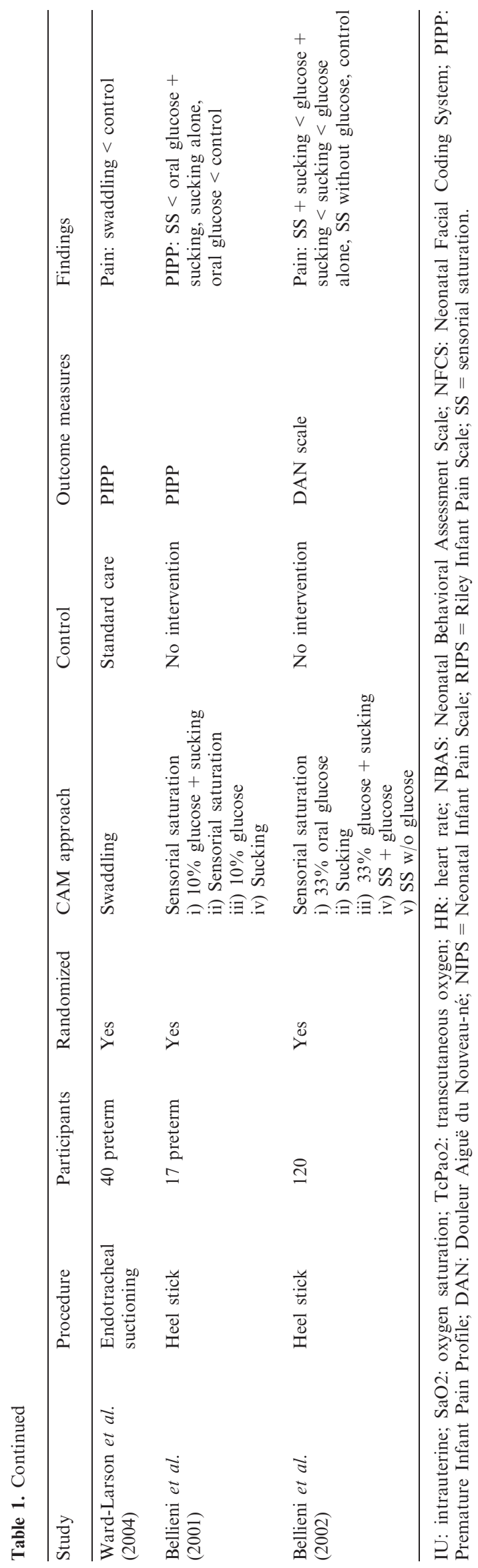

unanesthetized circumcision by comparing the following six conditions: classical music (tape recorded), intrauterine sounds (tape recorded), pacifier, music and pacifier, intrauterine sounds and pacifier or control (no intervention). Numerous indicators of pain response were assessed including heart rate, dysrhythmias, blood pressure and transcutaneous oxygen level. In addition, behavioral state was assessed using the Brazelton scale (26) by two raters who reported high inter-rater reliability (0.97). Nevertheless, none of the interventions demonstrated significant reductions in the outcome parameters. The authors maintained that the inclusion of baseline measures (which were unavailable) may have yielded evidence of more positive findings. This is one of the few existing reports that has compared the effects of music to alternative auditory stimuli, although the findings suggest that neither music nor intrauterine sounds lead to reductions in pain related to circumcision.

More recently, Joyce et al. (2001)(27) studied the effects of recorded music and EMLA cream on healthy-term neonates undergoing circumcision. Pain responses were assessed using the Riley Infant Pain Scale (RIPS), an instrument with adequate reliability and validity $(28,29)$. In addition, all procedures were videotaped and independent raters who were blinded to group assignment conducted the behavioral assessments of pain. Unfortunately, the design of this study makes it difficult to interpret the results. It appears that half of the infants were assigned to receive EMLA $(n=11)$ and the other half to receive a placebo cream $(n=12)$. Similarly, half of the infants were assigned to receive music $(n=11)$ or no music $(n=12)$. However, it is unclear which infants received which combination of interventions. Although it was reported that infants who received music had lower pain ratings, it is not known what proportion of these infants received EMLA versus placebo. Additional research is needed to compare these interventions individually as well as in combination.

\section{Kangaroo Care}

The findings of trials investigating the effects of $\mathrm{KC}$ on procedural pain are shown in Table $1 . \mathrm{KC}$ is advocated as a natural and non-invasive method of providing analgesia to newborns undergoing heel sticks and other painful procedures. The mother holds the child skinto-skin against her body at an upright $40^{\circ}$ to $60^{\circ}$ angle and covers it with her blouse or shirt; a second covering may be used to provide additional warmth. Maternal touch has been described as a major factor contributing to the growth and development of both animals and humans (30), and there is data to suggest that $\mathrm{KC}$ alleviates pain response through the state regulation effects of maternal contact $(31,32)$. Ludington-Hoe et al. (2003)(33) demonstrated the safety of this intervention in preterm infants by monitoring temperature and vital 
signs. However, developing a body of evidence for the efficacy of $\mathrm{KC}$ has proved problematic for two reasons: i) it is difficult to fully blind observers to the condition and ii) unless carefully instructed, some mothers may touch, stroke or murmur to the infant, introducing a potential confounding factor.

Gray et al. (2000)(34) demonstrated the analgesic effects of $\mathrm{KC}$ in healthy, full-term newborns undergoing heel sticks. Mothers in the $\mathrm{KC}$ group lay in bed and were given the babies to hold; they were asked not to rub the child's head, but could offer verbal comfort. The control newborns were given heel sticks while resting quietly in the crib. Infant distress was assessed by heart rate (monitored), cry behaviors (audiotaped and assessed by blinded observers) and facial grimaces (videotaped and assessed by observers, who were able to observe which infants were held by the mothers and which were left in the crib). The authors found significant reductions in crying $(85 \%)$ and grimacing $(65 \%)$ in the infants held by the mothers compared to the controls. Heart rates of the $\mathrm{KC}$ group did not increase significantly over baseline, whereas the heart rates of the control group rose significantly during the procedure and continued to be elevated after its completion. Failure to blind the raters of facial grimaces and the unknown differential effects of verbal comforting given by the mothers were major weaknesses of this trial.

Johnston et al. (2003)(35) conducted a rare investigation in which raters were fully blinded when assessing pain response. This trial used a single-blind crossover design to compare $\mathrm{KC}$ and swaddling in preterm newborns, with each infant exposed to both conditions in randomized order during routine heel sticks. In the $\mathrm{KC}$ condition, mothers held the babies upright against their bodies, providing maximum skin-to-skin contact; mothers were instructed not to talk to or to touch their faces to the babies' heads. The control group was swaddled in blankets, with heels exposed and laid prone in their cribs. Infant distress was assessed using the Premature Infant Pain Profile (PIPP) (36). The camera recording facial grimaces was placed in such a way that the mother could not be seen and only the infant's face appeared. The authors explicitly stated that raters were unaware of the hypotheses although they did not discuss assessment of the effectiveness of the blinding. Also, interrater reliability was not reported and the number of raters was not specified. Nevertheless, the results indicated that the PIPP scores for the KC newborns were significantly lower than those in the swaddling control group; no effects of condition order or illness severity were noted.

\section{Olfactory Stimuli}

Results of trials using olfactory stimuli for pain related to minor procedures are summarized in Table 1. Olfactory stimuli may exert analgesic effects by distracting the infant or in the case of maternal breast milk, may lead to a conditioned response to maternal contact/comfort. Since it may not be advisable to move a preterm infant or risk a temperature change to provide analgesia, a familiar pleasant smell offering olfactory comfort may be a simple and safe intervention to help alleviate minor procedural pain in infants.

Goubet et al. (2003)(37) randomized stable preterm newborns to venipuncture or heel stick and further divided each procedural group into three subsets: familiar odor (FAM), unfamiliar order (NFAM) and no odor (CONT). It is not clear whether this subgroup assignment was randomized. The FAM infants slept with a vanillinscented scarf placed in their incubators, which was removed in the morning. Prior to the procedure, the FAM and NFAM groups were exposed to the vanillin scarf, while the CONT group was given an unscented scarf. The observers scoring pain responses were unaware of the olfactory condition, but were not blinded to type of procedure. They observed no group differences in distress in the infants receiving heel sticks. However, during venipuncture, the FAM group showed no increase in crying over baseline, while both the NFAM and CONT groups increased their crying significantly during the procedure. These findings support the use of olfactory stimulation for analgesia in infants receiving venipuncture, but not during heel sticks. This latter result was supported by another research group who reported that newborns exposed to familiar odors show no significant reductions in crying during heel sticks (38).

In contrast, Rattaz et al. (2005)(39) more recently provided support for the calming effect of the odor of familiarized mother's milk on crying behavior in infants undergoing heel sticks. Infants were randomly assigned to one of four groups: mother's milk odor, familiarized vanillin scent, unfamiliar scent and standard care control. Infant crying, grimacing and head movements were recorded and coded from a video recording, although there is no mention as to whether coders were blinded to the procedure. Results indicated that infants who smelled their mother's milk showed significantly less agitation during the procedure than the other groups, although consistent with previous work, the familiarized odor of vanillin did not produce any significant calming effects. It is possible that these findings can be explained by the emotional and biological ties to the odor of breast milk. Maternal milk has chemosensory properties that carry through from the prenatal period to infancy and is an extremely familiar odor associated with feeding and comfort within the first few days of life (40). Thus, a particular relationship to breast milk may explain the infant's reduced agitation in this group. The findings nevertheless provide support for interventions involving the presentation of a comforting scent, such as breast milk, to infants undergoing painful procedures. 


\section{Swaddling}

The findings of reports evaluating the efficacy of swaddling for minor procedural pain are summarized in Table 1. Swaddling or 'facilitated tucking' (side-lying or supine position with flexed limbs close to the trunk) is often used to alleviate infant distress during medical procedures. Swaddling may promote the body's self-regulation by limiting motor activity and assist in modulating physiological responses to painful sensations (41).

Fearon et al. (1997)(42) compared responses to heel sticks among preterm infants in a crossover trial of swaddling and standard care. Some of the neonates were given pacifiers or other types of sensory stimulation during the procedures. The authors scored facial activity using the NFCS (20) and monitored heart rate. In infants born $\geq 31$ weeks post-conception, facial activity and heart rate decreased more rapidly in the swaddling condition. Newborns under 31 weeks of post-conceptual age, however, showed no significant variation in response. Heart rate and facial activity returned spontaneously to baseline when the procedure ended, suggesting that swaddling may only be beneficial for older infants. However, potential order effects were not tested and the differential effects of the pacifiers and other stimulation were not measured. Corff et al. (1995)(41) conducted a similar crossover study of preterm infants undergoing heel sticks during facilitated tucking or no intervention. The tucking intervention led to significantly less cry behavior and a more rapid return to baseline heart rate levels compared to no intervention. Again, there was no specific analysis of order effects.

A single meta-analysis of swaddling has been conducted by Prasopkittikun and Tilokskulchai (2003)(43), who reviewed four unpublished masters' theses. All the trials in this meta-analysis used a crossover design to evaluate swaddling versus no intervention during routine heel sticks. The results supported the effectiveness of swaddling for procedural pain, with mean effect sizes ranging from moderate $(0.53)$ to large $(0.79)$. However, it should be noted that these studies had not been published in peer-reviewed journals. In a report that appeared after this meta-analysis, Huang et al. (2004)(44) investigated the effects of swaddling versus containment for pain related to heel sticks and found only very minor differences in premature infants' heart rate, oxygen saturation and PIPP scores. Containment here was defined as keeping the infant's limbs in close proximity to its trunk to maintain a flexed stable posture. Significant differences were found at the 3rd- and 7th-minute post-heel stick with the swaddling group exhibiting less pain; however, no other differences were found. It is possible that both swaddling and containment acted in a similar manner to calm infants, but it is impossible to know without the inclusion of a control group. The authors suggest that swaddling and containment can be used interchangeably to alleviate infant's pain during procedures, but without further controlled investigations, this conclusion must be considered tentative.

In a well-designed trial that also appeared after the aforementioned meta-analysis, Ward-Larson et al. (2004)(45) examined facilitated tucking for pain related to endotracheal suctioning in very low birth weight (VLBW) neonates. A crossover design was used to compare the tucking intervention to standard NICU care, but employed prospective randomization to allow for analysis of potential order effects. Infant distress was rated using the PIPP (46). Tucked infants had significantly lower scores compared to standard care, and it was noted that there were no order effects. A major limitation however, was the potential bias of using only one PIPP rater-the lead investigator.

\section{Sensorial Saturation - A Multi-sensory Approach to Pain Management in Infants}

Results of investigations examining a multi-faceted intervention called 'sensorial saturation,' which incorporates several CAM techniques, for minor procedural pain are shown in Table 1. Carlo Bellieni and his fellow investigators $(47,48)$ have developed and studied this approach. In sensorial saturation, the therapist lays the newborn on its side with limbs flexed but unrestricted, visually stimulates the child by looking closely into its face, speaks to it gently, massages its face and back (with hands scented with a pleasant fragrance) and gives glucose by syringe to induce the baby to suck. The several sources of non-noxious stimulation (i.e. auditory, tactile, visual, olfactory, vestibular and gustatory) are thought to distract the infant's attention away from the painful stimulation leading to reductions in the pain response $(47,48)$.

The Bellieni group first examined this method in a randomized crossover trial of preterm infants during five different heel pricks in the NICU (48). They found reductions in pain response when infants received sensorial saturation relative to four other conditions: glucose given to stimulate sucking; glucose given with no sucking; water given with no sucking and no intervention (standard care). Infant pain response was videotaped and rated using the PIPP (46) by two independent raters who were blinded to four of the five conditions. However, the therapist's activities during sensorial saturation could not be concealed on the videotapes, thereby leading to potential bias. Another limitation was that the authors used univariate tests for the statistical comparisons, instead of employing multivariate analyses to compare all conditions simultaneously and to test for possible order effects.

A larger trial by Bellieni and colleagues (47) randomly assigned term infants undergoing heel stick to one of six 
conditions: glucose with sucking; glucose with no sucking; water with sucking; sensorial saturation; sensorial saturation with no glucose and standard care. Infant distress was assessed with the Douleur Aiguë du Nouveau-né (DAN)(49). As in their first investigation, it was not possible to blind raters to the sensorial saturation condition. Neonates given sensorial saturation with glucose showed significantly less pain response than the infants in the other conditions; those given water with sucking and glucose with sucking also showed significantly less pain response than infants who received standard care. Mean duration of crying was $25 \mathrm{~s}$ in the control group, compared to $7 \mathrm{~s}$ for the babies receiving glucose plus sucking and only $2.8 \mathrm{~s}$ for the newborns receiving sensorial saturation. These results with a larger sample of full-term newborns replicate those of the earlier report in preterm infants and offer further evidence for the efficacy of sensorial saturation. The possible bias resulting from non-blinding of the saturation condition remains a problem, however. Also, it is unclear how many behavioral raters were used and whether inter-rater reliability or other checks were conducted.

\section{Discussion}

The growing literature on CAM methods of pain management with infants suggests that there are safe non-pharmacological methods of providing at least partial pain relief for infants during the often frequent and painful procedures they must routinely undergo. The mechanisms by which these methods reduce pain response are unclear, but may include the promotion of natural self-regulatory processes as well as sensory distraction. Nevertheless, as discussed subsequently, the quality of the evidence for some modalities remains relatively weak, as few investigators reported adequate blinding and standardization of methods. A summary of the main findings for each of the CAM interventions reviewed is presented subsequently.

The available evidence suggests that music therapy may hold promise in reducing pain among infants receiving heel sticks (Table 1). On the other hand, there is mixed support for the application of music for circumcision pain. It should be noted that only a handful of studies on the effects of music on infant procedural pain have been conducted and no research has yet examined the differential effects of live music therapy and recorded music. Further, it is unclear whether music is more effective as a distraction than visual, tactile, nutritive or other stimuli, or whether music may reduce distress through an additional mechanism other than distraction. Work addressing each of these questions is required.

$\mathrm{KC}$ is an appealing method of pain management in infants undergoing painful medical procedures and appears to be safe for both term and preterm infants
(Table 1). However, only two trials on $\mathrm{KC}$ have been conducted, and the generalizability and standardization of this intervention is complicated by variations in maternal attitudes and comforting styles. In several trials, mothers introduced additional comforting techniques such as stroking or verbalization when providing $\mathrm{KC}$, which exerted unknown effects. Moreover, Johnston et al. (2003)(35) reported a 40\% refusal rate among mothers, indicating that not all women were comfortable with the approach; women who are less comfortable may be less effective in relieving their newborns' distress. Further research on this method and the variable impact of maternal style and attitude are indicated.

Use of a familiar pleasant smell is a low-risk, low-cost intervention that may distract the infant from procedural pain (Table 1). The two available trials showed that newborns familiarized to a vanillin scent evidenced reduced pain response during venipuncture, but not during heel sticks; however, the familiar smell of maternal breast milk was effective in providing analgesia for the latter. As with other research in this area, the evidence is qualified by the authors' failure to provide for or explain observer-blinding procedures.

Four trials and one meta-analysis of unpublished research offer preliminary evidence for the efficacy of swaddling in managing pain and distress caused by heel sticks in preterm infants (Table 1). In each of these, however, assessments were done by a non-blinded observer, who, in some cases, also provided the intervention. All but one investigation employed a crossover design, but order effects were generally not examined. No reports have evaluated swaddling in fullterm newborns or in painful procedures other than heel stick. It seems likely that swaddling, facilitated tucking or other interventions which gently support the baby in a naturally secure position may help to relieve procedural pain in neonates, but further well-designed research is needed.

Multisensory stimulation as tested by the Bellieni group in two reports appears to produce analgesic effects for both term and preterm infants undergoing heel sticks (Table 1). One major limitation of these trials however is their failure to fully blind observers. In addition, their larger 2002 investigation demonstrated that the saturation method without the administration of glucose caused infants to become irritable and to respond to the heel stick with increased signs of distress (47). Bellieni and colleagues argued on the basis of this observation that sensorial saturation will be most effective if there is a 'favorable background situation' (p. 462)(47), provided by the newborn sucking a sweet liquid. Yet, the Johnston group failed to find a similar 'favorable background' effect in their work on simulated rocking with sucrose; the addition of the sugar stimulus did not significantly enhance pain reduction (50). It may be that specific stimuli alone provide a high degree of distraction or 
comfort, while the introduction of multiple unfamiliar and less comforting stimuli acts to heighten rather than distract the infant's attention. It is clear that further research on the incremental effects of individual components of the sensorial saturation package is necessary.

\section{Conclusions}

The available evidence suggests that there are a number of potentially effective CAM interventions that can safely alleviate the pain and distress among preterm and fullterm infants undergoing painful medical procedures. Many of the modalities described earlier need to be evaluated in controlled trials with adequate sample sizes and well-validated behavioral measures, and assessed by raters who are blinded to experimental condition. A few studies have shown that blinding with a well-placed camera is possible for these therapies. Researchers should also be encouraged to use and fully describe randomization procedures, statistical methods, effect sizes and adequate reliabilities for behavioral ratings. For minor procedures, trials are needed to further assess the efficacy of such methods as $\mathrm{KC}$, swaddling, olfactory stimulation and music-based interventions against sucrose, and against standard pharmacological analgesics in both healthy and preterm/sick infants. In addition, more work is needed to investigate the benefits of CAM approaches as adjuncts to conventional analgesics for major procedures such as circumcision, surgery and mechanical ventilation.

Other CAM modalities for which no research in neonates exists may also deserve attention. Massage, e.g. is often very comforting and has been shown to be effective among adults for specific pain complaints (51). Moreover, a few experienced researchers have found that a standardized massage protocol can contribute to the growth and development of stable preterm newborns (52, 53). Yet many NICUs maintain a 'minimal touch' standard, following the recommendations of earlier authorities, who found that premature babies often suffered from blood oxygen desaturation as a result of constant routine handling during examinations and daily care (54). Well-designed and carefully monitored trials of therapeutic massage in preterm and full-term infants are needed to determine the safety and efficacy of this modality for daily care and as an analgesic for procedural and organic pain.

Finally, it is crucial that the field develop clear guidelines, based on good evidence, of which approaches - CAM, conventional analgesic, or a combination of these - provide the safest and most reliable analgesia for full-term or preterm newborns, for healthy or sick infants and for babies of different ages through the immediate neonatal period. It is unknown which CAM approaches are best suited for which painful procedures, and for which infants (e.g. term infants versus preterm and/or sick infants). Our ability to ensure infants' health and survival through effective care should be matched by our ability to do so with minimum levels of pain and distress.

\section{Acknowledgements}

Research by the authors is supported in part by R01 DE12754 awarded by the National Institute of Dental and Craniofacial Research (PI: Zeltzer) and R01 MH063779 awarded by the National Institutes of Mental Health (PI: Jacob).

\section{References}

1. Tsao JCI, Zeltzer LK. Complementary and alternative medicine approaches for pediatric pain: a review of the state-of-the-science. Evid Based Complement Alternat Med 2005;2:149-59.

2. Davis MP, Darden PM. Use of complementary and alternative medicine by children in the United States. Arch Pediatr Adolesc Med 2003;157:393-6.

3. Ottolini MC, Hamburger EK, Loprieato JO, Coleman RH, Sachs HC, Madden R, et al. Complementary and alternative medicine use among children in the Washington, DC area. Ambul Pediatr 2001;1:122-5.

4. Simpson N, Pearce A, Finlay F, Lenton S. The use of complementary medicine in paediatric outpatient clinics. Ambul Child Health 1998;3:351-6.

5. Grootenhuis MA, Last BF, de Graaf-Nijkerk JH, van der Wel M. Use of alternative treatment in pediatric oncology. Cancer Nurs 1998;21:282-8.

6. Neuhouser ML, Patterson RE, Schwartz SM, Hedderson MM, Bowen DJ, Standish LJ. Use of alternative medicine by children with cancer in Washington state. Prev Med 2001;33:347-54.

7. Stern RC, Canda ER, Doershuk CF. Use of nonmedical treatment by cystic fibrosis patients. J Adolesc Health 1992;13:612-5.

8. Bellas A, Lafferty WE, Lind B, Tyree PT. Frequency, predictors, and expenditures for pediatric insurance claims for complementary and alternative medical professionals in Washington state. Arch Pediatr Adolesc Med 2005;159:367-72.

9. Simons SH, van Dijk M, Anand KS, Roofthooft D, van Lingen RA, Tibboel D. Do we still hurt newborn babies? A prospective study of procedural pain and analgesia in neonates. Arch Pediatr Adolesc Med 2003;157:1058-64.

10. Beider S, Moyer CA. Randomized controlled trials of pediatric massage: a review. Evid Based Complement Alternat Med 2007; 4:23-34.

11. Hermann C, Blanchard EB. Biofeedback in the treatment of headache and other childhood pain. Appl Psychophysiol Biofeedback 2002;27:143-62.

12. Holden EW, Deichmann MM, Levy JD. Empirically supported treatments in pediatric psychology: recurrent pediatric headache. J Pediatr Psychol 1999;24:91-109.

13. Wild MR, Espie CA. The efficacy of hypnosis in the reduction of procedural pain and distress in pediatric oncology: a systematic review. J Dev Behav Pediatr 2004;25:207-13.

14. Kemper KJ, Danhauer SC. Music as therapy. South Med J 2005;98:282-8.

15. Standley JM. A meta-analysis of the efficacy of music therapy for premature infants. J Pediatr Nurs 2002;17:107-13.

16. Kellman N. Noise in the intensive care nursery. Neonatal Netw 2002;21:35-41.

17. Arntz A, Dreessen L, Merckelbach H. Attention, not anxiety, influences pain. Behav Res Ther 1991;29:41-50.

18. Farthing GW, Venturino M, Brown SW. Suggestion and distraction in the control of pain: test of two hypotheses. J Abnorm Psychol 1984;93:266-76. 
19. Butt ML, Kisilevsky BS. Music modulates behaviour of premature infants following heel lance. Can J Nurs Res 2000;31:17-39.

20. Grunau RV, Craig KD. Pain expression in neonates: facial action and cry. Pain 1987;28:395-410.

21. Craig KD, Whitfield MF, Grunau RV, Linton J, Hadjistavropoulos HD. Pain in the preterm neonate: behavioural and physiological indices. Pain 1993;52:287-99.

22. Johnston CC, Stevens B, Craig KD, Grunau RV. Developmental changes in pain expression in premature, full-term, two- and fourmonth-old infants. Pain 1993;52:201-8.

23. Bo LK, Callaghan P. Soothing pain-elicited distress in Chinese neonates. Pediatrics 2000;105:E49.

24. Lawrence J, Alcock D, McGrath P, Kay J, MacMurray SB, Dulberg C. The development of a tool to assess neonatal pain. Neonatal Netw 1993;12:59-66.

25. Marchette L, Main R, Redick E, Bagg A, Leatherland J. Pain reduction interventions during neonatal circumcision. Nurs Res 1991;40:241-4.

26. Brazelton TB. Neonatal Behavioral Assessment Scale. Philadelphia: Lippincott, 1973.

27. Joyce BA, Keck JF, Gerkensmeyer J. Evaluation of pain management interventions for neonatal circumcision pain. $J$ Pediatr Health Care 2001;15:105-14.

28. Joyce BA, Schade JG, Keck JF, Gerkensmeyer J, Raftery T, Moser S, et al. Reliability and validity of preverbal pain assessment tools. Issues Compr Pediatr Nurs 1994;17:121-35.

29. Schade JG, Joyce BA, Gerkensmeyer J, Keck JF. Comparison of three preverbal scales for postoperative pain assessment in a diverse pediatric sample. J Pain Symptom Manage 1996;12:348-59.

30. Fleming AS, O'Day DH, Kraemer GW. Neurobiology of motherinfant interactions: experience and central nervous system plasticity across development and generations. Neurosci Biobehav Rev 1999:23:673-85.

31. Ludington-Hoe SM, Nguyen N, Swinth JY, Satyshur RD. Kangaroo care compared to incubators in maintaining body warmth in preterm infants. Biol Res Nurs 2000;2:60-73.

32. de Leeuw R, Colin EM, Dunnebier EA, Mirmiran M. Physiological effects of kangaroo care in very small preterm infants. Biol Neonate 1991;59:149-55

33. Ludington-Hoe SM, Ferreira C, Swinth J, Ceccardi JJ. Safe criteria and procedure for kangaroo care with intubated preterm infants. J Obstet Gynecol Neonatal Nurs 2003;32:579-88.

34. Gray L, Watt L, Blass EM. Skin-to-skin contact is analgesic in healthy newborns. Pediatrics 2000;105:e14.

35. Johnston CC, Stevens B, Pinelli J, Gibbins S, Filion F, Jack A, et al. Kangaroo care is effective in diminishing pain response in preterm neonates. Arch Pediatr Adolesc Med 2003;157:1084-8.

36. Stevens B, Johnston C, Franck L, Petryshen P, Jack A, Foster G. The efficacy of developmentally sensitive interventions and sucrose for relieving procedural pain in very low birth weight neonates. Nurs Res 1999;48:35-43.

37. Goubet N, Rattaz C, Pierrat V, Bullinger A, Lequien P. Olfactory experience mediates response to pain in preterm newborns. Dev Psychobiol 2003;42:171-80.
38. Kawakami K, Takai-Kawakami K, Okazaki Y, Kurihara H, Shimizu Y, Yanaihara T. The effects of odors on human newborn infants under stress. Infant Behav Dev 1997;20:531-5.

39. Rattaz C, Goubet N, Bullinger A. The calming effect of a familiar odor on full-term newborns. $J$ Dev Behav Pediatr 2005;26:86-92

40. Schaal B, Marlier L, Soussignan R. Human foetuses learn odours from their pregnant mother's diet. Chem Senses 2000;25:729-37.

41. Corff KE, Seideman R, Venkataraman PS, Lutes L, Yates B. Facilitated tucking: a nonpharmacologic comfort measure for pain in preterm neonates. J Obstet Gynecol Neonatal Nurs 1995;24:143-7.

42. Fearon I, Kisilevsky BS, Hains SM, Muir DW, Tranmer J. Swaddling after heel lance: age-specific effects on behavioral recovery in preterm infants. J Dev Behav Pediatr 1997;18:222-32.

43. Prasopkittikun T, Tilokskulchai F. Management of pain from heel stick in neonates: an analysis of research conducted in Thailand. J Perinat Neonatal Nurs 2003;17:304-12.

44. Huang CM, Tung WS, Kuo LL, Ying-Ju C. Comparison of pain responses of premature infants to the heelstick between containment and swaddling. $J$ Nurs Res 2004;12:31-40.

45. Ward-Larson C, Horn RA, Gosnell F. The efficacy of facilitated tucking for relieving procedural pain of endotracheal suctioning in very low birthweight infants. MCN Am J Matern Child Nurs 2004;29:151-6.

46. Stevens B, Johnston C, Petryshen P, Taddio A. Premature infant pain profile: development and initial validation. Clin $J$ Pain 1996; 12:13-22

47. Bellieni CV, Bagnoli F, Perrone S, Nenci A, Cordelli DM, Fusi M, et al. Effect of multisensory stimulation on analgesia in term neonates: a randomized controlled trial. Pediatr Res 2002;51:460-3.

48. Bellieni CV, Buonocore G, Nenci A, Franci N, Cordelli DM, Bagnoli F. Sensorial saturation: an effective analgesic tool for heelprick in preterm infants: a prospective randomized trial. Biol Neonate 2001;80:15-8.

49. Carbajal R, Paupe A, Hoenn E, Lenclen R, Olivier-Martin M. APN: evaluation behavioral scale of acute pain in newborn infants. Arch Pediatr 1997:4:623-8

50. Johnston CC, Stremler RL, Stevens BJ, Horton LJ. Effectiveness of oral sucrose and simulated rocking on pain response in preterm neonates. Pain 1997;72:193-9.

51. Tsao JCI. Effectiveness of massage therapy for chronic, nonmalignant pain: a review. Evid Based Complement Alternat Med in press;doi: 10.1093/ecam/nel109.

52. Dieter JN, Field T, Hernandez-Reif M, Emory EK, Redzepi M. Stable preterm infants gain more weight and sleep less after five days of massage therapy. J Pediatr Psychol 2003;28:403-11.

53. Field T. Preterm infant massage therapy studies: an American approach. Semin Neonatol 2002;7:487-94.

54. Long JG, Alastair GS, Philip MB, Lucey JF. Excessive handling as a cause of hypoxemia. Pediatrics 1980;65:203-7.

Received February 9, 2007; accepted April 24, 2007 


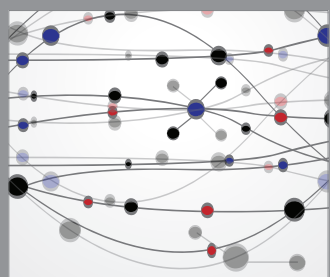

The Scientific World Journal
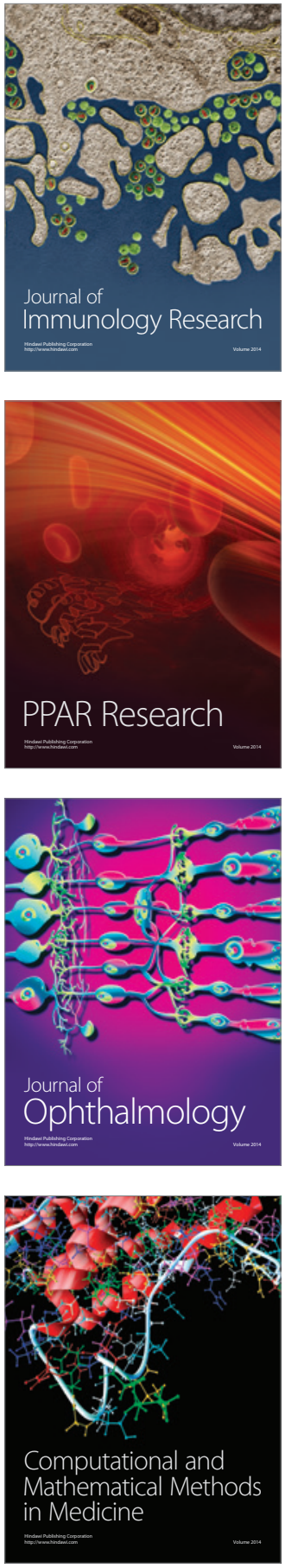

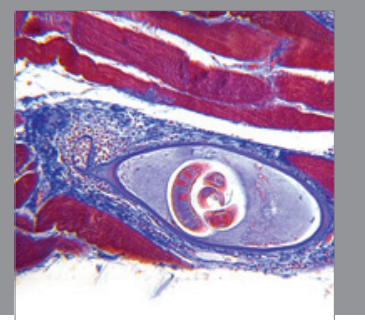

Gastroenterology

Research and Practice
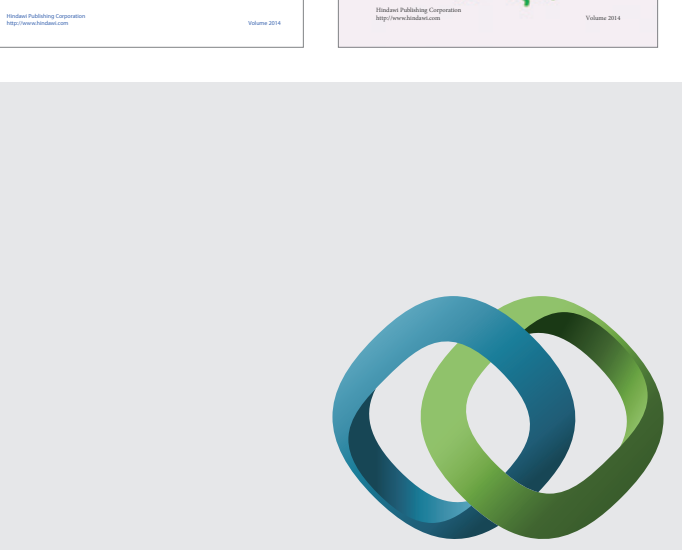

\section{Hindawi}

Submit your manuscripts at

http://www.hindawi.com
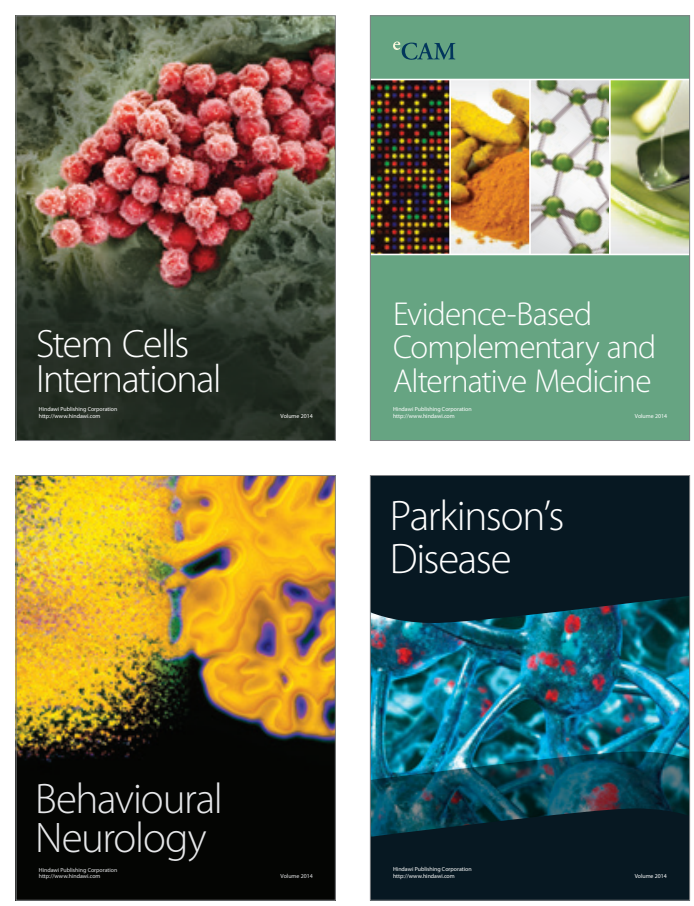

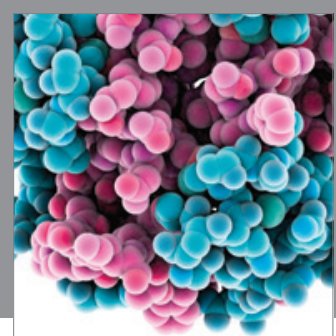

Journal of
Diabetes Research

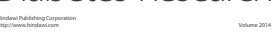

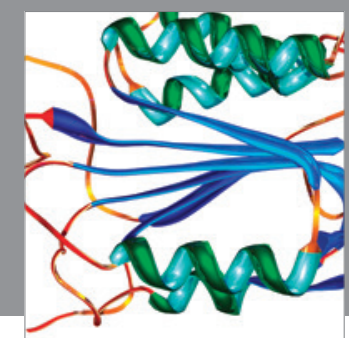

Disease Markers
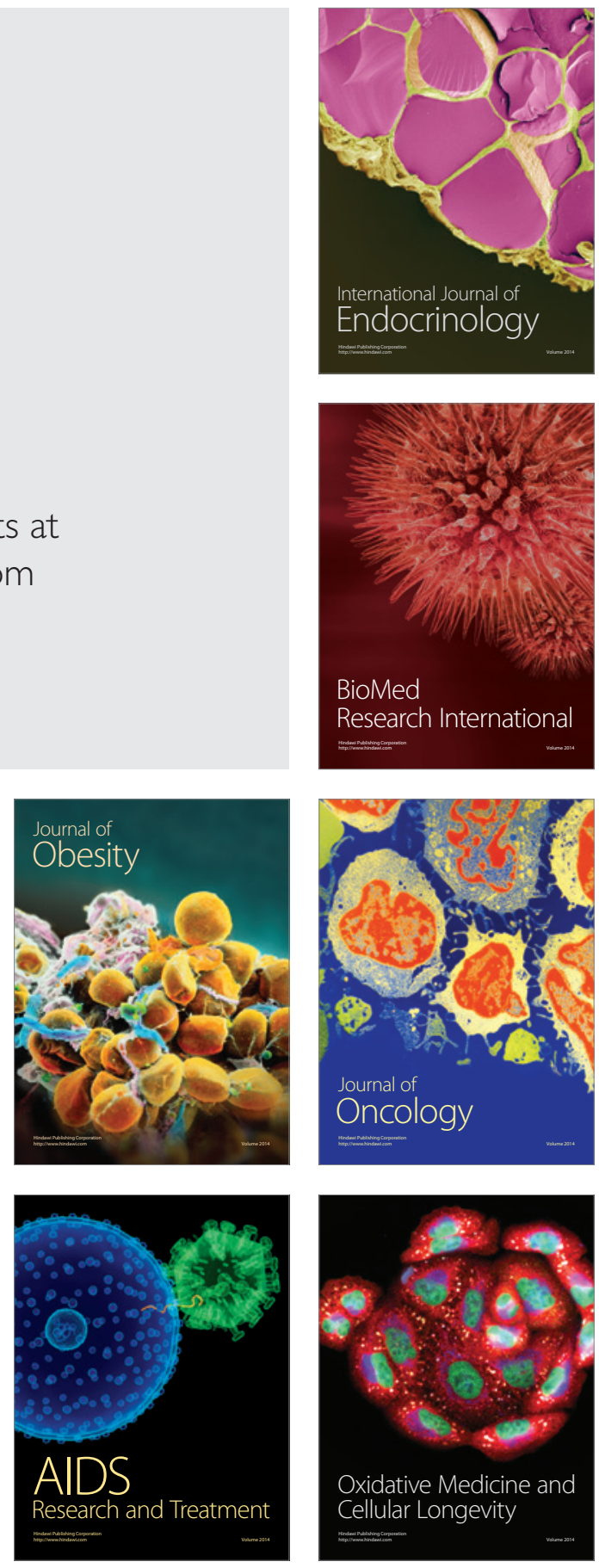